\title{
Molecular Assessment of Non-Muscle Invasive and Muscle Invasive Bladder Tumors: Mapping of Putative Urothelial Stem Cells and Toll-Like Receptors (TLR) Signaling
}

\author{
Rafael Mamprin Stopiglia1, Wagner Eduardo Matheus ${ }^{1 *}$, Patrick Vianna Garcia ${ }^{2}$, \\ Athanase Billis ${ }^{3}$, Mariana Anteghini Castilho ${ }^{4}$, Vitor Hugo Figueiredo de Jesus ${ }^{4}$, \\ Ubirajara Ferreira ${ }^{1}$, Wagner José Fávaro ${ }^{2}$

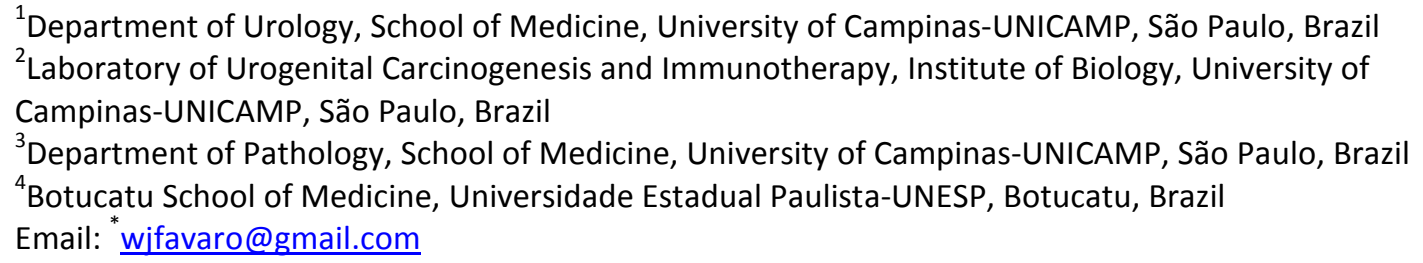

Received 31 December 2014; accepted 27 January 2015; published 29 January 2015

Copyright (C) 2015 by authors and Scientific Research Publishing Inc.

This work is licensed under the Creative Commons Attribution International License (CC BY). http://creativecommons.org/licenses/by/4.0/

(c) (i) Open Access

\section{Abstract}

Purpose: The main objectives of this study were to characterize and compare the urothelial stem cells (healthy and cancer cells) and TLRs features in the urinary bladder of men without lesions and with non-muscle-invasive and muscle invasive urothelial tumors. Materials and Methods: Thirty samples of the urinary bladder of 50 to 80-year-old men, with and without diagnosis of malignant urothelial lesions were used. The 30 samples were divided into 3 groups $(n=10$ per group): Normal Group; Non-Muscle Invasive Bladder Cancer Group; Muscle Invasive Bladder Cancer Group. The samples were histopathologically and immunohistochemically analyzed. The study was conducted at teaching Hospital of the University of Campinas (UNICAMP). Results: The CD44 and CD133 immunoreactivities were significantly intense in the muscle-invasive cancer group when compared to the other groups. The ABCG2 biomarker demonstrated intense immunoreactivities in both non-muscle and muscle invasive groups, and absent immunoreactivity in the normal group. All groups showed weak CD117 immunoreactivity. Putative Healthy Stem Cells (CD44/CD133/ $\mathrm{CD117}^{+}$) occurred in all groups. Putative Cancer Stem Cells (CD44/CD133/ABCG2+) only occurred

${ }^{*}$ Corresponding author.

How to cite this paper: Stopiglia, R.M., et al. (2015) Molecular Assessment of Non-Muscle Invasive and Muscle Invasive Bladder Tumors: Mapping of Putative Urothelial Stem Cells and Toll-Like Receptors (TLR) Signaling. Journal of Cancer Therapy, 6, 129-140. http://dx.doi.org/10.4236/jct.2015.62014 
in the non-muscle and muscle invasive cancer groups. TLR2 immunoreactivity was significantly lower in the non-muscle invasive cancer group and absent in the muscle invasive cancer group. TLR4 immunoreactivity was significantly lower in both cancer groups. Conclusions: This study leads us to the conclusion that putative cancer stem cell occurrence was sensitive to the decreased in TLR2 and TLR4 immunoreactivities. Also, TLR2 and TLR4 demonstrated their involvement in the regulation of the different biomarkers for putative healthy and cancer urothelial stem cells, probably acting as negative regulators of urothelial carcinogenesis. Taken together data obtained suggest that use of TLRs agonists could be a promising alternative for the treatment of non-muscle and muscle invasive bladder tumors.

\section{Keywords} Non-Muscle Invasive Bladder Cancer, Muscle Invasive Bladder Cancer, Toll-Like Receptors, Cancer
Stem Cell, Stem Cells Biomarkers

\section{Introduction}

Most of the bladder tumors ( $>90 \%)$ are urothelial carcinomas for they originate in the urothelium [1]. An electronic microscope analysis revealed that the basal cell layer is always in contact with the basal membrane; the intermediate cell layer, occasionally, but never involving the superficial cells or umbrella cells [2]. This bladder epithelium acts as a constant permeable barrier and protects the blood from toxic urinary substances [3].

In over $70 \%$ of the cases, bladder cancer (BC) is superficial (pTa and pT1) or non-muscle invasive, and the occurrence of a muscle invasive disease is less frequent [4]. Over $50 \%$ of the non-muscle invasive tumors recur in 4 years after the initial treatment, of which 11\% develop into the invasive form [5].

The high recurrence frequency of the urinary bladder urothelial cells carcinoma, as well as its heterogeneous presentation support the hypothesis that adult stem cells (or cells that acquire stem characteristics by mutation) may be involved in the development and recurrence of this type of tumor [6].

In different types of cancers, a very small population of cells has been recognized as healthy stem cells (HSC) and cancer stem cells (CSC), for they have self-renewal and differentiation capacities [7]. Both the origin and the frequency of the stem cells are not yet clear [8]. In the bladder, the hypothesis is that these cells originate in the basal lamina [9] or in the epithelial-mesenchymal transition [10].

Since the discovery of stem cells, researches have focused on identifying markers for these cells. However, although many of the markers have already been described, none have proven to be exclusive or specific [11]. Several cell surface markers have been used to characterize healthy and cancer stem cells, especially the surface antigens CD44, CD117 and CD133 and the ATP Binding Cassette membrane transporter (ABCG2) [12].

In turn, the toll-like receptors (TLRs) are a family of transmembrane receptors that recognizes conserved molecular patterns of microbial origin, known for their molecular patterns associated to pathogens [13]. They also have a fundamental role in tissue repair due to inflammation [14]. The TLRs classic function is antimicrobial: they recruit leukocytes for infected tissues and subsequently induce adaptive immune responses. The TLR signal transduction is made via different adaptive proteins that activate signaling cascades involving the $\kappa \mathrm{B}(\mathrm{NF}-\kappa \mathrm{B})$ nuclear transition factor.

Initially, the TLRs we identified only in immune and epithelial cells. However, recent studies have demonstrated that these receptors may also play a functional, yet controversial, role in cancer, for there are conflicting data that point them out as negative or positive carcinogenesis regulators [15].

Thus, the main objectives of this study were to characterize and compare putative cancer urothelial stem cells (healthy and cancer cells) and TLRs profiles in the urinary bladder of men with and without non-muscle-invasive and muscle-invasive tumors.

\section{Materials and Methods}

In this study, we used 30 samples of urinary bladder tissue of men between 50 and 80 years of age (average 61 years old), with and without diagnosis of urothelial lesions, obtained from The Teaching Hospital of the School of Medicine, University of Campinas (UNICAMP). Ten urinary bladder samples were from necropsy of patients 
without diagnosis of urothelial lesions and/or urologic disease. The remaining 20 urinary bladder samples came from patients submitted to transurethral resection and radical cystectomy. The patients were distributed into 3 groups ( $n=10$ samples per group): Normal Group (without lesion); Non-Muscle Invasive Bladder Cancer Group and Muscle Invasive Cancer Group. The samples were further processed and submitted to histopathological and immunohistochemical analyses.

\subsection{Histopathological Analysis}

All urinary bladder samples were fixed by immersion in 10\% buffered formaldehyde, embedded in paraplast (Paraplast Plus, Brazil), cut into 6- $\mu \mathrm{m}$ thick sections, stained with Hematoxylin-Eosin and photographed with a Zeiss Axiophot (Zeiss, Hamburg, Germany) photomicroscope.

The histopathological analyses were classified according to the staging consensus proposed by the WHO and by the International Society of Urologic Pathology [16].

\subsection{Immunolabelled CD44, CD133, CD117, ATP Binding Cassette Membrane Transporter (ABCG2), Toll-Like Receptors (TLR) 2 and 4}

All urinary bladder samples, the same used for histopathological analysis, were taken and cut into $6 \mu \mathrm{m}$ thick sections. Different protocols were used for antigen retrieval. After, the sections were incubated in $0.3 \% \mathrm{H}_{2} \mathrm{O}_{2}$ to block endogenous peroxidase at room temperature. Primary rabbit polyclonal ab41478 (abcam, USA) for CD44, rabbit polyclonal ab5506 (abcam, USA) for CD117, rabbit polyclonal ab16518 (abcam, USA) for CD133, rabbit polyclonal B-25 sc-130933 (Santa Cruz Biotchenollogy, USA) for ABCG2, rabbit polyclonal ABBI-251110 (Abbiotec, USA) for TLR2 and rabbit polyclonal ABBI-251111 (Abbiotec, EUA) for TLR4.

In order to assess the intensity of the antigen immunoreactivities, the percentage of positive urothelial bladder cells was tested in 10 fields for each antibody with a 400× magnification. The marker intensity was measured in a 0 - 3 scale and expressed as 0 (absence of immunoreactivity: $0 \%$ of positive urothelial cells); 1 (weak immunoreactivity: 1\% - 35\% of positive urothelial cells); 2 (moderate immunoreactivity: 36\% - 70\% of positive urothelial cells); and 3 (intense immunoreactivity: $>70 \%$ of positive urothelial cells) [17].

\subsection{Statistical Analysis}

The quantified parameters (histopathological and immunohistochemical analyses) were statistically analyzed for the different groups and the differences among the groups were assessed with the ratio test. In all analyses, the type I error probability was indicated in each test conducted and $\mathrm{p}<0.05$ was considered statistically significant.

\section{Results}

\subsection{Histopathological Analysis}

The urothelium of the samples of the normal group did not present structural changes. This epithelium consisted of a layer of superficial (or highly differentiated umbrella cells), intermediary and basal cells (Figure 1(a)).

The samples of the non-muscle invasive group presented histopathological alterations, of which the most significantly frequent were papillary carcinoma (pTa) and urothelial carcinoma with lamina propria invasion (pT1), occurring in 50\% and 30\% of the patients, respectively (Figures 1(c)-(e); Table 1). Histopathological changes, such as carcinoma in situ (pTis) were also identified in $20 \%$ of the patients (Figure 1(b); Table 1).

The papillary carcinoma (pTa) was characterized for its large papillary lesions. The cells were disorderly arranged, with polarity loss. Pronounced cellular atypias were evidenced as large pleomorphic hyperchromatic nuclei with prominent nucleoli (Figure 1(d)).

The urothelial carcinoma with lamina propria invasion (pT1) was characterized by tumor cells arranged in small groups near the surface urothelium within the lamina propria (Figure 1(e)). These cells presented eosinophilic cytoplasm and pleomorphic nuclei (Figure 1(e)).

In the muscle invasive group, the most frequent urothelial lesions observed in $50 \%$ and $30 \%$ of the patients were carcinoma with muscularis propria invasion (pT2) and carcinoma with microscopic extravesical invasion (pT3a), respectively (Table 1). The urothelial carcinoma with muscularis propria invasion (pT2) was characterized by cancer cells arranged in small groups with diffuse infiltration in the stroma. The cells presented eosi- 


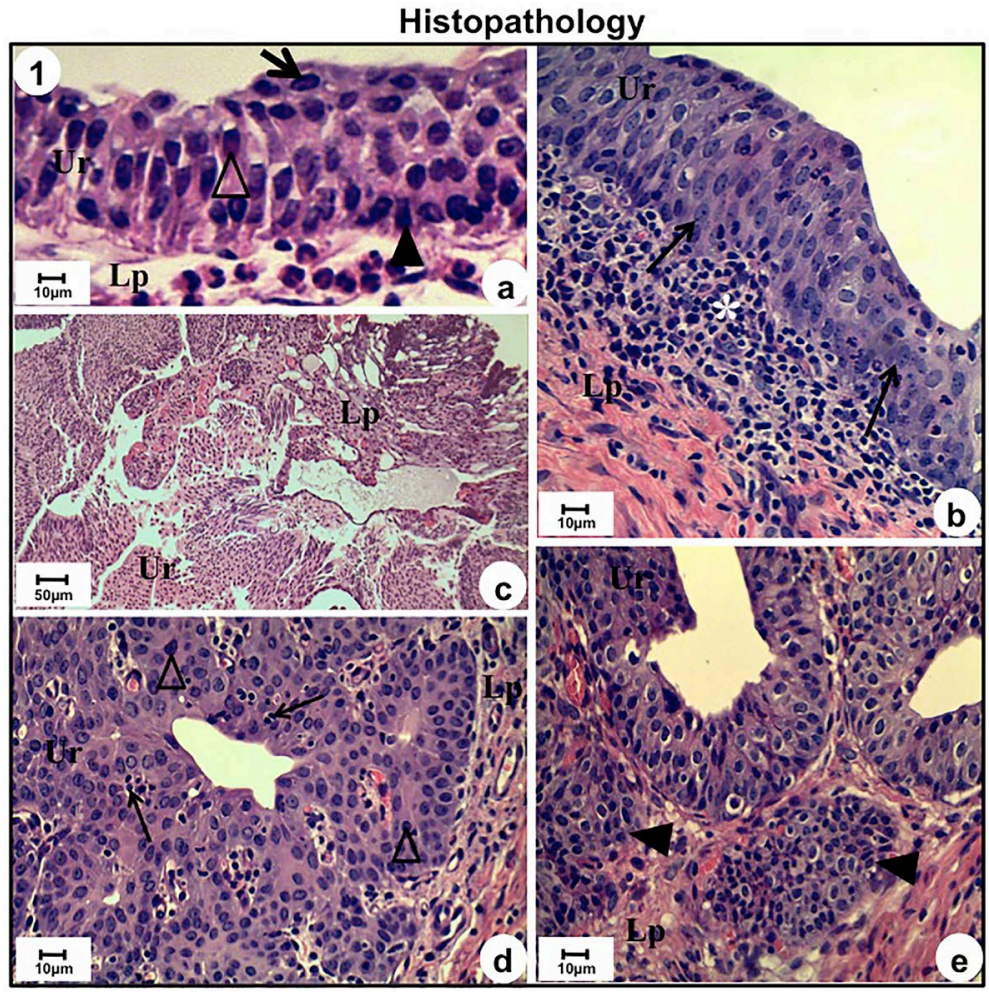

Figures 1. (a)-(e): Photomicrographs of the urinary bladder from Normal (a) and Non-Muscle Invasive ((b), (c), (d), (e)) groups. (a) Normal urothelium consisting of superficial cells (arrow), intermediary (open arrowhead) and basal (closed arrowhead); (b) Carcinoma in situ: pronounced cell atypia characterized by volumous nuclei (arrows) and multiple and evident nucleoli; inflammatory infiltrate in lamina propria (asterisk); (c) and (d) Papillary carcinoma with large papillary lesions, hyperchromatic nuclei (open arrowheads) and mitotic figures (arrows); (e) Carcinoma with lamina propria invasion: cancer cells gathered in small groups or strings (closed arrowheads). In (a)-(e): Lplamina propria, $\mathrm{Ur}$ - urothelium.

Table 1. Percentage of histopathological changes in the urinary bladder from Normal, Non-Muscle Invasive and Muscle Invasive groups.

\begin{tabular}{|c|c|c|c|}
\hline \multirow[b]{2}{*}{ Histopathology } & \multicolumn{2}{|r|}{ Groups } & \multirow[b]{2}{*}{$\begin{array}{l}\text { Muscle Invasive } \\
\quad(\mathbf{n}=10)\end{array}$} \\
\hline & $\begin{array}{l}\text { Normal } \\
(\mathrm{n}=10)\end{array}$ & $\begin{array}{l}\text { Non-Muscle Invasive } \\
\quad(\mathbf{n}=10)\end{array}$ & \\
\hline Flat Hyperplasia & - & - & - \\
\hline Papillary Hyperplasia & - & - & - \\
\hline Low-Grade Intraurothelial Neoplasia & - & - & - \\
\hline High-Grade Intraurothelial Neoplasia—Carcinoma in situ (pTis) & - & $02(20.0 \%)^{*}$ & - \\
\hline Papillary Carcinoma (pTa) & - & $05(50.0 \%)^{*}$ & - \\
\hline Carcinoma with Lamina Propria Invasion (pT1) & - & $03(30.0 \%)^{*}$ & - \\
\hline High-Grade Carcinoma with Muscularis Propria Invasion (pT2) & - & - & $05(50.0 \%)^{*}$ \\
\hline High-Grade Carcinoma with Microscopic Extravesical Invasion (pT3a) & - & - & $03(30.0 \%)^{*}$ \\
\hline $\begin{array}{l}\text { High-Grade Carcinoma with Macroscopically } \\
\text { Apparent Extravesical Invasion (pT3b) }\end{array}$ & - & - & $02(20.0 \%)^{*}$ \\
\hline Normal & 10 (100.0\%) & - & - \\
\hline
\end{tabular}

*Statistically significant difference (ratio test, $P<0.0001$ ). 
nophilic or amphophilic cytoplasm and abundant hyperchromatic nuclei, which were highly pleomorphic, with irregular and angular outline and evident nucleoli (Figure 2(a) and Figure 2(b)). Only a small amount of neoplastic vascular emboli were identified in this tumor stage (Figure 2(c)).

Both the high degree urothelial carcinoma with microscopic extravesical invasion (pT3a) and that with macroscopic apparent extravesical invasion (pT3b) were characterized by cells with eosinophilic cytoplasm, a large
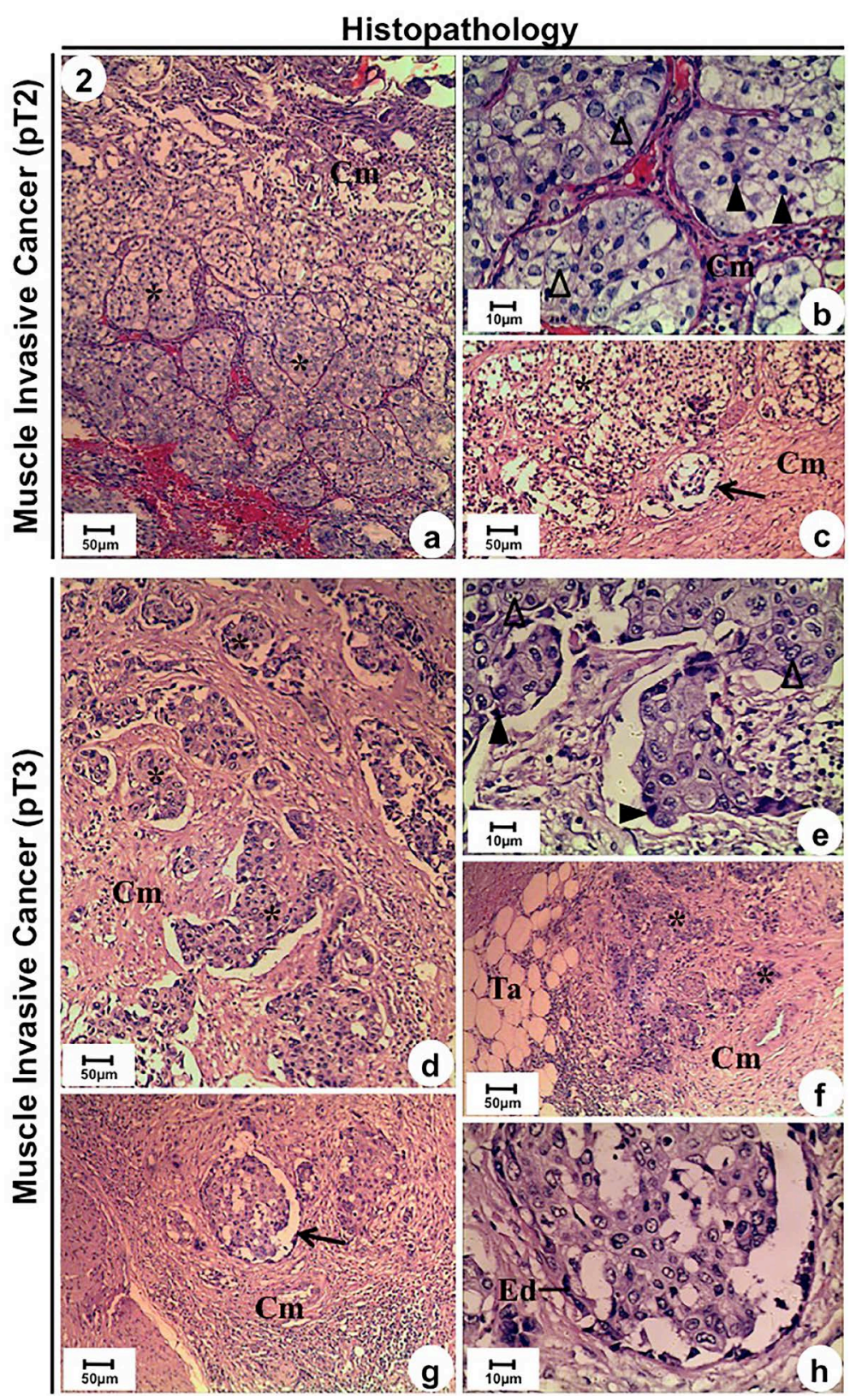

Figure 2. (a)-(h): Photomicrographs of the urinary bladder from Muscle Invasive group with muscularis propria invasion ((a), (b), (c)) and extravesical invasion ((d), (e), (f), (g), (h)). (a) and (b) High-grade urothelial carcinoma with diffuse muscularis propria invasion (pT2) characterized by cells gathered in small group (asterisks); pronounced cell atypia with volumous nuclei (open arrowheads) and hyperchromatic (closed arrowheads); multiple and evident nucleoli; (c) Few neoplastic vascular emboli (arrow); (d), (e) and (f) High grade urothelial carcinoma with extravesical invasion (pT3) characterized by neoplastic cells grouped in nests (asterisks), with infiltration in the perivesical adipose tissue (Ta); volumous nuclei with irregular and vesiculous outlines (open arrowheads); nuclei; (g) and (h) Great number of neoplastic vascular emboli (arrow); vascular endothelium (Ed). In (a)-(h): Cm-muscularis propria layer. 
number of hyperchromatic nuclei and mitotic figures (Figure 2(d), Figure 2(e) and Figure 2(h); Table 1). The nuclei were highly pleomorphic, vesiculous, with irregular and angular outlines, evident nucleoli and loss of cell polarity (Figure 2(e) and Figure 2(h)). Several neoplastic emboli were identified in this tumor stage (Figure 2(g) and Figure 2(h)). The pT3 tumor stage was characterized by cancer cells that were either isolated or grouped in small nests (Figure 2(d) and Figure 2(f)). The perivesical adipose tissue was focally identified demonstrating neoplasia (Figure 2(f)).

\subsection{Immunolabelled CD44, CD133, CD117, ABCG2, TLRs 2 and 4}

Only the papillary carcinoma tumor (pTa) samples were used for the different immunohistochemistries in the non-muscle invasive cancer group, which represented the most frequent stage. In the muscle invasive cancer group, only the samples of tumors with muscularis propria invasion were used (pT2) were analyzed.

CD44 and CD133 immunoreactivities were intense in the urothelial cells of the muscle invasive cancer group, moderate in the non-muscle invasive cancer group and weak in the normal group (Figures 3(a)-(d), Figure 4(a) and Figure 4(b); Table 2). The three groups did not differ significantly in CD117 immunoreactivity, demonstrating weak immunoreactivity in urothelial cells (Figure 3(e), Figure 3(f) and Figure 4(c); Table 2).

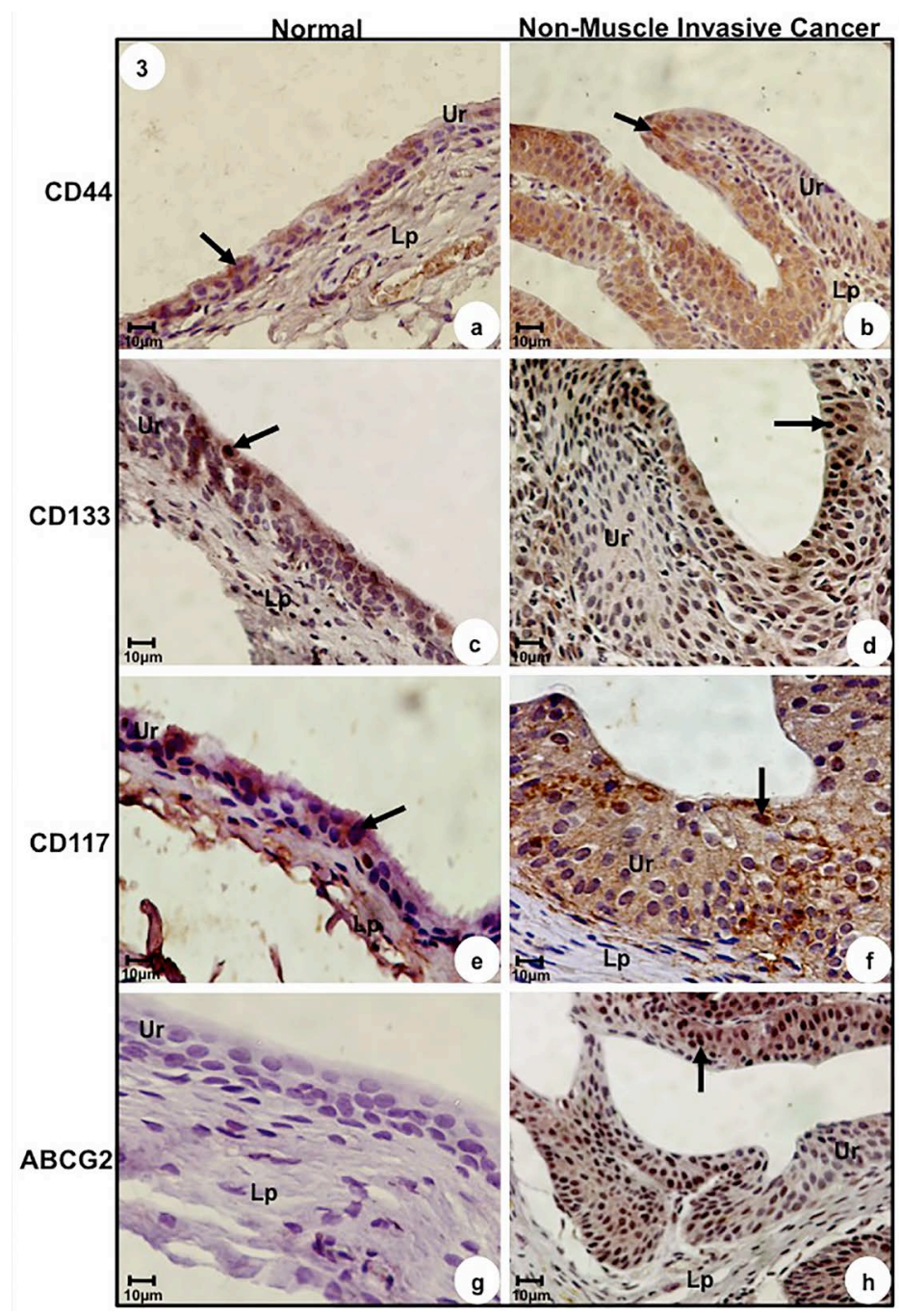

Figure 3. Immunolabelled of the urinary bladder from Normal ((a), (c), (e), (g)) and Non-Muscle Invasive ((b), (d), (f), (h)) groups. (a) and (b) CD44 immunoreactivity (arrow) in the urothelium; (c) and (d) CD133 immunoreactivity (arrow) in the urothelium; (e) and (f) CD117 immunoreactivity (arrow) in the urothelium; (g) and (h) ABCG2 immunoreactivity (arrow) in the urothelium. In (a)-(h): Lp-lamina propria, Ur-urothelium. 


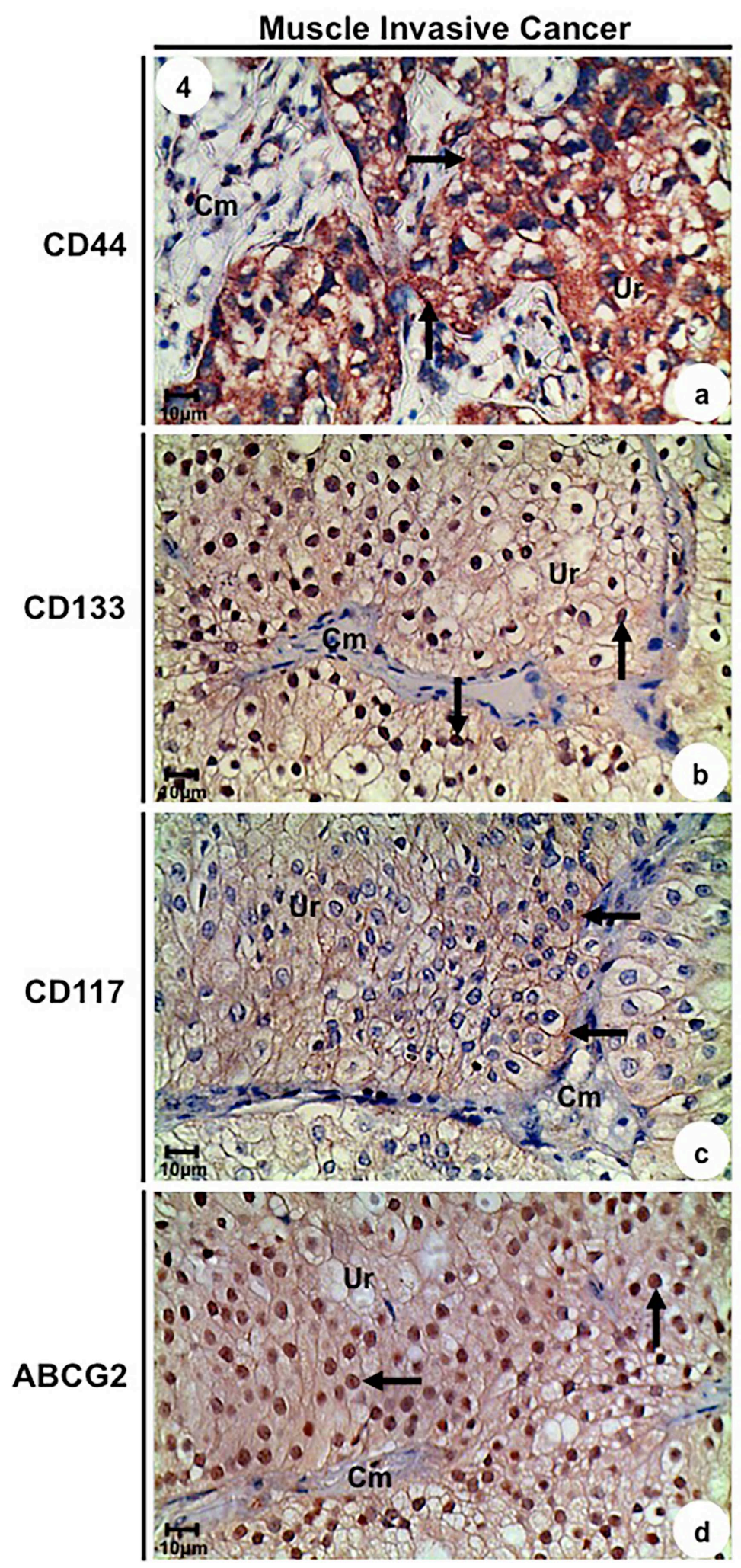

Figure 4. Immunolabelled of the urinary bladder from Muscle Invasive group. (a) CD44 immunoreactivity (arrows) in the urothelium; (b) CD133 immunoreactivity (arrows) in the urothelium; (c) CD117 immunoreactivity (arrows) in the urothelium; (d) ABCG2 immunoreactivity (arrows) in the urothelium. In (a)-(d): Cmmuscularis propria layer, Ur-urothelium. 
Table 2. Immunolabelled antigens intensity of the urothelial cells in the urinary bladder from Normal, Non-Muscle Invasive and Muscle Invasive groups.

\begin{tabular}{cccc}
\hline & \multicolumn{3}{c}{ Groups } \\
\hline Antigens & Control $(\mathbf{n}=\mathbf{1 0})$ & Non-Muscle Invasive $(\mathbf{n}=\mathbf{1 0})$ & Muscle Invasive (n= 10) \\
\hline CD44 & $1(15.0 \%)$ & $2(54.1 \%)^{*}$ & $3(71.2 \%)^{*}$ \\
CD117 & $1(22.9 \%)$ & $1(33.5 \%)$ & $1(27.6 \%)$ \\
CD133 & $1(5.0 \%)$ & $2(34.0 \%)^{*}$ & $3(94.5 \%)^{*}$ \\
ABCG2 & $0(0.0 \%)$ & $3(94.8 \%)^{*}$ & $3(97.4 \%)^{*}$ \\
TLR2 & $3(96.2 \%)^{*}$ & $1(11.2 \%)$ & $0(0.0 \%)$ \\
TLR4 & $3(87.4 \%)^{*}$ & $1(10.3 \%)$ & $1(12.1 \%)$ \\
\hline
\end{tabular}

0, absence of immunoreactivity; 1 , low immunoreactivity (1\% - 35\% of positive urothelial cells); 2 , moderate immunoreactivity (36\% - 70\% of positive urothelial cells); 3 , high immunoreactivity ( $>70 \%$ of positive urothelial cells). ${ }^{*}$ Statistically significant difference (ratio test, $\left.P<0.0001\right)$.

On the other hand, ABCG2 immunoreactivity was absent in the normal group, whereas the non-muscle invasive and muscle invasive cancer groups showed intense immunoreactivity in the urothelial cells (Figure 3(g), Figure 3(h), Figure 4(d); Table 2).

Putative Healthy Stem Cells (HSCs) and Putative Cancer Stem Cells (CSCs) were identified in all cell layers of the urothelium (umbrella, intermediary and basal cells). HSCs were positive for CD44/CD133/CD117 and were present in all three groups. CSCs were positive for ABCG2/CD44/CD133 and were more frequently observed in the muscle invasive cancer group in relation to non-muscle invasive cancer group. Also, CSCs were not verified in the normal group.

The TLRs 2 and 4 were specifically assessed and identified in view of their greater correlation with the urothelium. TLR2 and TLR4 immunoreactivities were significantly lower in pT2 and pTa tumors when compared to normal samples (Figures 5(a)-(f); Table 2). TLR2 immunoreactivity was absent in the pT2 tumor.

\section{Discussion}

Approximately $70 \%$ to $80 \%$ of the bladder tumors are non-muscle invasive, the majority of which stage Ta and the remaining T1 or Tis. The Ta tumors are generally low-grade while most of the T1 tumors are high-grade. By definition, thecarcinoma in situ (Tis) is a high-grade tumor and represents $10 \%$ of the bladder tumors. In $50 \%$ of the cases, the Tis is associated with papillary or invasive tumor (secondary Tis), while the other 50\% occur isolatedly (primary Tis) [18]. Most of the cases of bladder cancer have high recurrence probability [19].

A relevant number of risk factors have been associated to the development of bladder cancer, such as occupational exposure to aromatic amines and to organic chemical substances in various professional activities. However, smoking is one of the most important risk factors, responsible for over 33\% of the cases of bladder cancer [20] [21]. Furthermore, the cancers may possibly originate from the CSCs, and, hypothetically, the latter are responsible for the occurrence of metastasis and tumor relapse after an initial treatment, as well as for the invasive characteristics of the tumors determined by the stem cell ability to interact with the stroma [22]. The recent identification of cancer stem cells in the bladder as mediators of resistance to conventional therapies make these cells candidates to biological target therapies [1].

Epithelial tumors contain a heterogeneous cell population and this may be characterized by histopathological and functional properties differences, such as anchorage-independent growth, proliferative and apoptotic capacities and responses to therapy. Recent evidences point out to the existence of a cell hierarchy in epithelial tumors, and the cancer stem cells are at the top of this hierarchy [22].

There are two proposed mechanisms for the occurrence of CSC in different tumors: oncogenic mutations, which inactivate the expansion of normal stem cells or in a cell that is more differentiated by oncogenic mutations that may cause a continuous proliferation of cells that will not go into a differentiated postmitotic state, creating a population of self-renewal cells in which these mutations may accumulate [23]. Cancer treatment failures may be associated to the low effects of these agents over the CSCs, which maintain their total ability to reestablish tumoral cell masses [24]. 

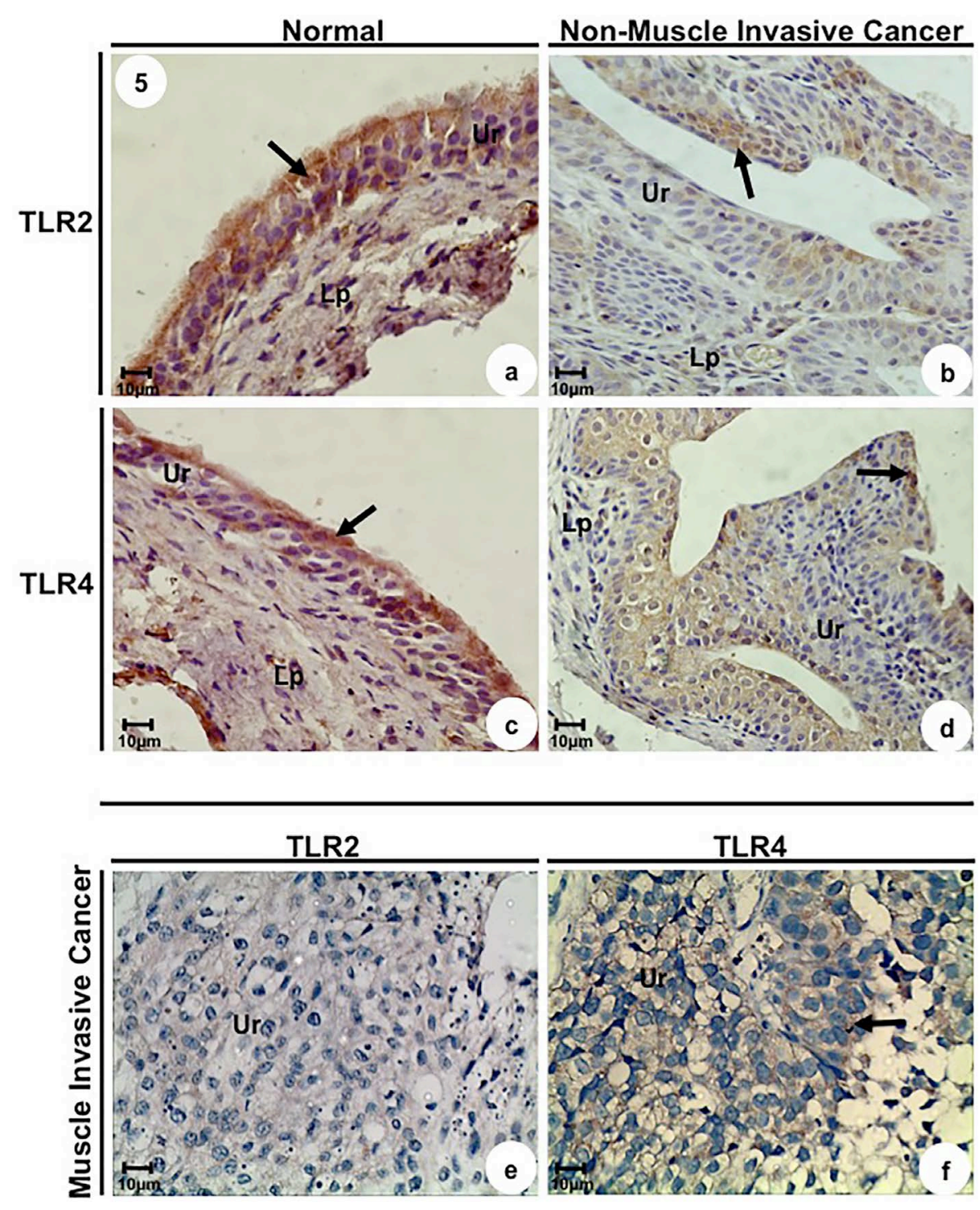

Figure 5. Immunolabelled of the urinary bladder from Normal ((a), (c)), Non-Muscle Invasive ((b), (d)) and Muscle Invasive ((e), (f)) groups. (a), (b) and (e) TLR2 immunoreactivity (arrow) in the urothelium. (c), (d) and (f) TLR4 immunoreactivity (arrow) in the urothelium. In (a)-(f): $\mathrm{Lp}$-lamina propria, $\mathrm{Ur}$ - urothelium.

Cell surface markers, such as CD44, CD133 and ABCG2, are considered the most common markers to identify normal and cancer stem cells [25]. CD44 is a transmembrane glycoprotein that is expressed in practically all cell types and acts in cell-cell and cell-extracellular matrix interactions; it also participates in growth regulation by presenting growth factors to its cell surface receptors [26]. Several studies have demonstrated that the CD44 expression seems to play a fundamental role in the migration of cancer cells and tumor progression, and also has prognostic value in certain types of cancer [27].

In turn, CD133 (prominin-1) is a plasma membrane glycoprotein that is expressed in cell protrusions of several organs and tumors. Cells that are positive for CD133 have 3 important stem cell features: they are rare, they have high proliferation potential and they are able to reconstitute highly branched ductal-like structures [28]. CD117, also known as c-Kit, is a potential stem cell marker that is mainly expressed in the basal epithelial compartment of the prostate area near the urethra [29].

The ATP Binding Cassette (ABCG2) membrane transporter has been used as a possible CSC marker and is associated to the development of multi-resistance to drugs [30]. 
In addition, TLRs are expressed both in the normal and neoplastic urothelium. Ayari et al. [31] identified TLRs 2 and 4 in healthy urothelium and non-invasive tumors with much lower intensities in the last detection. This expression was markedly reduced in invasive muscle urothelial tumors [31]. Very similar results were found in this study, averaging around 10\% in the normal group and 90\% in groups with tumors for both receptors intensities. Also, Fávaro et al. [32] demonstrated in appropriate animal model for non-muscle invasive bladder cancer significant decrease of TLRs 2 and 4 protein levels in animals with non-muscle invasive cancer in relation to normal animals.

The TLR role in cancer is a controversial issue, for there are conflicting data that point them out as negative or positive carcinogenesis regulators. They also have a fundamental role in tissue repair due to inflammation [14]. TLR activation may cause tumor regression by increasing vascular permeability and through the recruitment of leukocytes, which determines tumor cell lysis by natural killer (NK) and cytotoxic T cells [13]-[15]. The contradictory evidence that TLR promotes carcinogenesis, whereas in others it exerts antitumor effects, could be explained by the different intensity and nature of the inflammatory response [15]. In fact, chronic inflammatory processes are milder than acute inflammatory responses, which are aimed at inducing pathogen clearance. In most cases, cancer-associated inflammation is similar to chronic inflammation, including the production of factors that stimulate tissue repair and cancer cell survival and proliferation [14] [15]. However, if the inflammatory response develops into acute inflammation, an immune effector mechanism is activated, and cancer regression takes place [14] [15]. Among the different elements that control neoplastic processes, a major role is attributed to members of the chemokine superfamily. Chemokines expressed by tumor cells and by host cells play a critical role in determining the fate of the developing tumor by regulating the migration of different leukocyte subtypes [14] [15]. The relative proportion of each defense cell type (macrophages, T cells, NK cells, dendritic cells, or other leukocyte subtypes) within the tumor largely dictates the immune profile at the tumor site; local production of numerous inflammatory mediators is crucial for the recruitment and activation of leukocytes in addition to macrophages and mast cells [14] [15]. In particular, CD8 T cells and some types of innate immune cells, such as NK cells, can protect against experimental tumor growth [14] [15].

These studies demonstrate that activation of TLR4 signaling in cancer cells correlates with tumor progression through various mechanisms, by escape immune surveillance thereby preventing the attack of the host defense system.

This study demonstrated that TLR2 and TLR4 immunoreactivities were significantly lower in low-grade nonmuscle invasive (pTa stage) and muscle invasive (pT2 stage) tumors, and this may contribute to the high tumor relapse and progression rates.

\section{Conclusion}

This study leads us to the conclusion that cancer stem cell occurrence was sensitive to the decreased in TLR2 and TLR4 immunoreactivities. Also, TLR2 and TLR4 demonstrated their involvement in the regulation of the different biomarkers for healthy and cancer urothelial stem cells, probably acting as negative regulators of urothelial carcinogenesis. Taken together data obtained suggest that use of TLRs agonists could be a promising alternative for the treatment of non-muscle and muscle invasive bladder tumors.

\section{Acknowledgements}

Support by São Paulo Research Foundation (FAPESP_Process Number 2012/50014-5 and 2011/14223-6).

\section{References}

[1] Bryan, R.T. (2011) Bladder Cancer and Cancer Stem Cells: Basic Science and Implications for Therapy. The Scientific World Journal, 11, 1187-1194. http://dx.doi.org/10.1100/tsw.2011.117

[2] Hatina, J. and Schulz, W.A. (2012) Stem Cells in the Biology of Normal Urothelium and Urothelium Carcinoma. Neoplasma, 59, 728-736. http://dx.doi.org/10.4149/neo_2012_089

[3] Zupancic, D., Zakrajsek, M., Zhou, G. and Romih, R. (2011) Expression and Localization of Four Uroplakins in Urothelial Preneoplastic Lesions. Histochemistry and Cell Biology, 136, 491-500. http://dx.doi.org/10.1007/s00418-011-0857-4

[4] Kroft, S.H. and Oyasu, R. (1994) Urinary Bladder Cancer: Mechanisms of Development and Progression. Laboratory Investigation, 71, 158-174. 
[5] Shimada, K., Fujii, T., Anai, S., Fujimoto, K. and Konishi, N. (2011) ROS Generation via NOX4 and Its Utility in the Cytological Diagnosis of Urothelial Carcinoma of the Urinary Bladder. BMC Urology, 11, 22. http://dx.doi.org/10.1186/1471-2490-11-22

[6] Bentivegna, A., Conconi, D., Panzeri, E., Sala, E., Bovo, G., Vigano, P., Brunelli, S., Bossi, M., Tredici, G., Strada, G. and Dalpra, L. (2010) Biological Heterogeneity of Putative Bladder Cancer Stem-Like Cell Populations from Human Bladder Transitional Cell Carcinoma Samples. Cancer Science, 101, 416-424. http://dx.doi.org/10.1111/j.1349-7006.2009.01414.X

[7] Tang, Y., Hamburger, A.W., Wang, L., Khan, M.A. and Hussain, A. (2010) Androgen Deprivation and Stem Cell Markers in Prostate Cancers. International Journal of Clinical and Experimental Pathology, 10, 128-138.

[8] Moltzahn, F.R., Volkmer, J.P., Rottke, D. and Ackermann, R. (2008) Cancer Stem Cells-Lessons from Hercules to Fight the Hydra. Urologic Oncology, 26, 581-589. http://dx.doi.org/10.1016/j.urolonc.2008.07.009

[9] Gaisa, N.T., Graham, T.A., McDonald, S.A., Canadillas-Lopez, S., Poulsom, R. and Heidenreich, A. (2011) The Human Urothelium Consists of Multiple Clonal Units, Each Maintained by a Stem Cell. The Journal of Pathology, 225, 163-171. http://dx.doi.org/10.1002/path.2945

[10] McConkey, D.J., Lee, S., Choi, W., Tran, M. and Majewski, T. (2010) Molecular Genetics of Bladder Cancer: Emerging Mechanisms of Tumor Initiation and Progression. Urologic Oncology, 28, 429-440. http://dx.doi.org/10.1016/j.urolonc.2010.04.008

[11] Visvader, J.E. and Lindeman, G.J. (2008) Cancer Stem Cells in Solid Tumors: Accumulating Evidence and Unresolved Questions. Nature Reviews Cancer, 8, 755-768. http://dx.doi.org/10.1038/nrc2499

[12] Richardson, G.D., Robson, C.N., Lang, S.H., Neal, D.E., Maitland, N.J. and Collins, A.T. (2006) CD133, a Novel Marker for Human Prostatic Epithelial Stem Cells. Journal of Cell Science, 117, 3539-3545. http://dx.doi.org/10.1242/jcs.01222

[13] Akira, S., Uematsu, S. and Takeuchi, O. (2006) Pathogen Recognition and Innate Immunity. Cell, 124, $783-801$. http://dx.doi.org/10.1016/j.cell.2006.02.015

[14] Srikrishna, G. and Freeze, H.H. (2009) Endogenous Damage-Associated Molecular Pattern Molecules at the Crossroads of Inflammation and Cancer. Neoplasia, 11, 615-628.

[15] Rakoff-Nahoum, S. and Medzhitov, R. (2009) Toll-Like Receptors and Cancer. Nature Reviews Cancer, 9, 57-63. http://dx.doi.org/10.1038/nrc2541

[16] Epstein, J.L., Amin, M.B., Reuter, V.R. and Mostoli, F.K., Bladder Consensus Conference Committee (1998) The World Health Organization/International Society of Urological Pathology Consensus Classification of Urothelial (Transitional Cell) Neoplasms of the Urinary Bladder. American Journal of Surgical Pathology, 22, 1435-1448. http://dx.doi.org/10.1097/00000478-199812000-00001

[17] Fávaro, W.J., Hetzl, A.C., Reis, L.O., Ferreira, U., Billis, A. and Cagnon, V.H. (2012) Periacinar Retraction Clefting in Nonneoplastic and Neoplastic Prostatic Glands: Artifact or Molecular Involvement. Pathology \& Oncology Research, 18, 285-292. http://dx.doi.org/10.1007/s12253-011-9440-5

[18] Messing, E.M. (2002) Urothelial Tumors of the Urinary Tract. In: Walsh, P.C., Retik, A.B., Vaughan Jr., E.D., et al., Eds., Campbell's Urology, 8th Edition, Saunders, Philadelphia, 2732-2784.

[19] Borden Jr., L.S., Clark, P.E. and Hall, M.C. (2005) Bladder Cancer. Current Opinion in Oncology, 17, $275-280$. http://dx.doi.org/10.1097/01.cco.0000156985.47984.9e

[20] Zeegers, M.P., Tan, F.E. and Dorant, E. (2000) The Impact of Characteristics of Cigarette Smoking on Urinary Tract Cancer Risk: A Meta-Analysis of Epidemiologic Studies. Cancer, 89, 630-639. http://dx.doi.org/10.1002/1097-0142(20000801)89:3<630::AID-CNCR19>3.0.CO;2-Q

[21] Grimmer, G., Dettbarn, G. and Seidel, A. (2000) Detection of Carcinogenic Aromatic Amines in the Urine of NonSmokers. Science of the Total Environment, 247, 81-90. http://dx.doi.org/10.1016/S0048-9697(99)00471-4

[22] Fabian, A., Barok, M., Vereb, G. and Szollosi, J. (2009) Die Hard: Are Cancer Stem Cells the Bruce Willises of Tumor Biology? Cytometry Part A, 75, 67-74. http://dx.doi.org/10.1002/cyto.a.20690

[23] Pardal, R., Clarke, M.F. and Morrison, S.J. (2003) Applying the Principles of Stem-Cell Biology to Cancer. Nature Reviews Cancer, 3, 895-902. http://dx.doi.org/10.1038/nrc1232

[24] Bentivegna, A., Conconi, D., Panzeri, E., Sala, E., Bovo, G., Vigano, P., Brunelli, S., Bossi, M., Tredici, G., Strada, G. and Dalpra, L. (2010) Biological Heterogeneity of Putative Bladder Cancer Stem-Like Cell Populations from Human Bladder Transitional Cell Carcinoma Samples. Cancer Science, 101, 416-424. http://dx.doi.org/10.1111/j.1349-7006.2009.01414.x

[25] Miki, J. (2009) Investigations of Prostate Epithelial Stem Cells and Prostate Cancer Stem Cells. International Journal of Urology, 17, 139-147. http://dx.doi.org/10.1111/j.1442-2042.2009.02438.x 
[26] Alam, T.N., O’hare, M.J., Laczko, I., Freeman, A., Al-Beidh, F., Masters, J.R. and Hudson, D.L. (2004) Differential Expression of CD44 during Human Prostate Epithelial Cell Differentiation. Journal of Histochemistry Cytochemistry, 52, 1083-1090. http://dx.doi.org/10.1369/jhc.4A6256.2004

[27] Ugolkov, A.V., Eisengart, L.J., Luan, C. and Yang, X.J. (2010) Expression Analysis of Putative Stem Cell Markers in Human Benign and Malignant Prostate. Prostate, 71, 18-25. http://dx.doi.org/10.1002/pros.21217

[28] Taylor, R.A. and Risbridger, G.P. (2008) The Path toward Identifying Prostatic Stem Cells. Differentiation, 76, 671681. http://dx.doi.org/10.1111/j.1432-0436.2008.00289.x

[29] Leong, K.G., Wang, B.E., Johnson, L. and Gao, W.Q. (2008) Generation of a Prostate from a Single Adult Stem Cell. Nature, 456, 804-808. http://dx.doi.org/10.1038/nature07427

[30] Kasper, S. (2009) Identification, Characterization, and Biological Relevance of Prostate Cancer Stem Cells from Clinical Specimens. Urologic Oncology, 27, 301-303. http://dx.doi.org/10.1016/j.urolonc.2008.12.012

[31] Ayari, C., Bergeron, A., LaRue, H., Menard, C. and Fradet, Y. (2011) Toll-Like Receptors in Normal and Malignant Human Bladders. Journal of Urology, 185, 1915-1921. http://dx.doi.org/10.1016/j.juro.2010.12.097

[32] Fávaro, W.J., Nunes, O.S., Seiva, F.R., Nunes, I.S., Woolhiser, L.K., Duran, N. and Lenaerts, A.J. (2012) Effects of P-MAPA Immunomodulator on Toll-Like Receptors and p53: Potential Therapeutic Strategies for Infectious Diseases and Cancer. Infectious Agents and Cancer, 7, 14. http://dx.doi.org/10.1186/1750-9378-7-14 
Scientific Research Publishing (SCIRP) is one of the largest Open Access journal publishers. It is currently publishing more than 200 open access, online, peer-reviewed journals covering a wide range of academic disciplines. SCIRP serves the worldwide academic communities and contributes to the progress and application of science with its publication.

Other selected journals from SCIRP are listed as below. Submit your manuscript to us via either submit@scirp.org or Online Submission Portal.
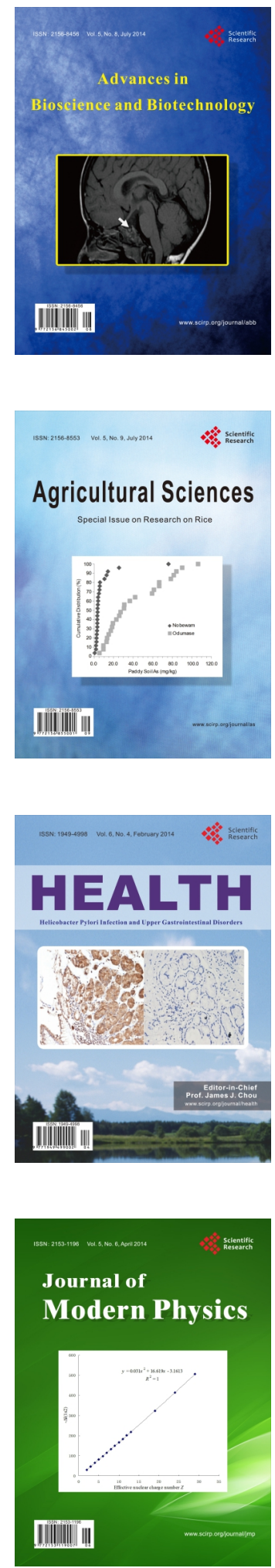
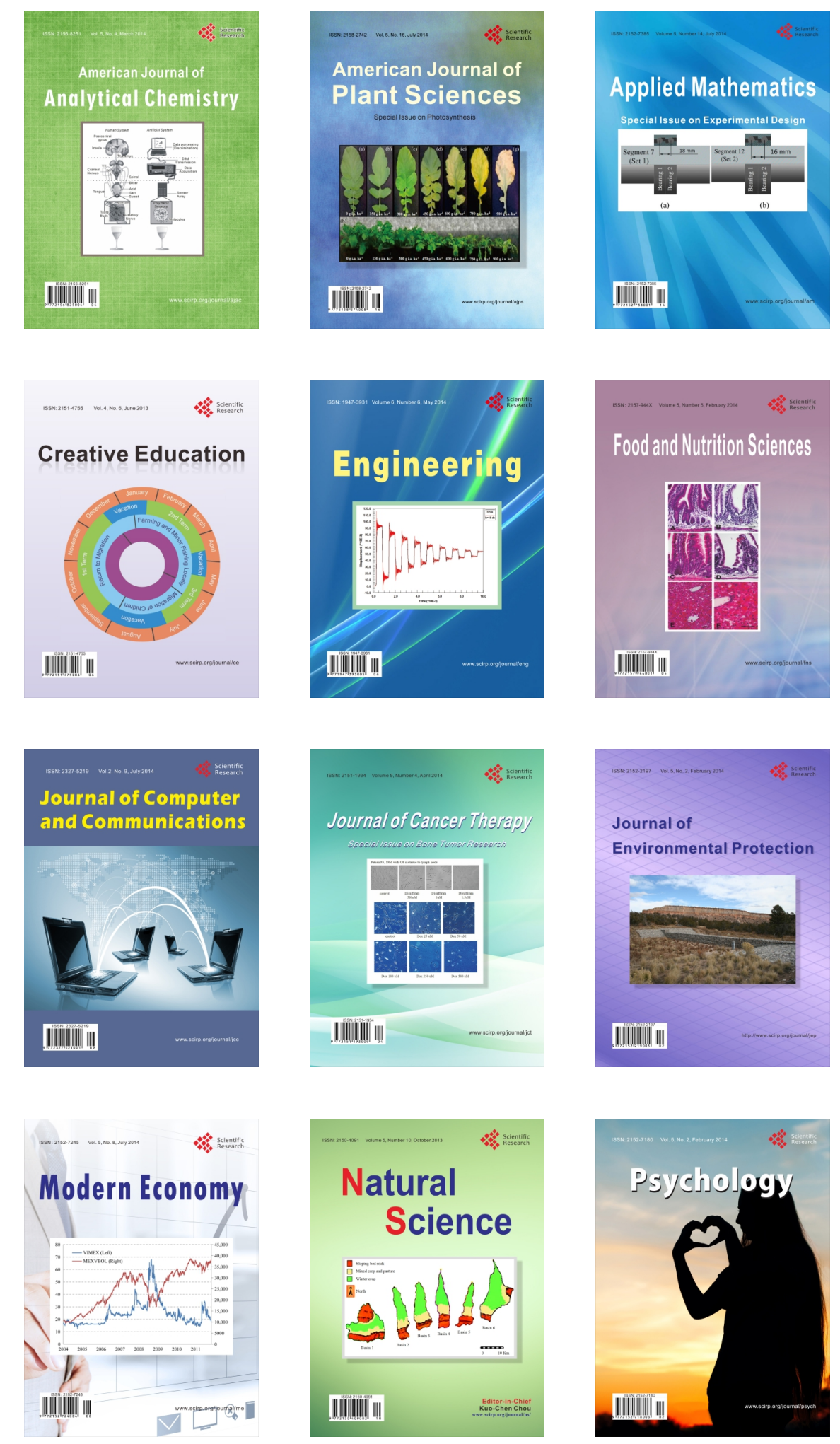